\title{
Colonoscopic study of 50 patients with colonic tuberculosis
}

\author{
S Shah, V Thomas, M Mathan, A Chacko, G Chandy, B S Ramakrishna, D D K Rolston
}

\begin{abstract}
Fifty patients with colonic tuberculosis are reported in whom a colonoscopic diagnosis confirmed by histological examination was possible in 40. Bacteriological studies did not increase the diagnostic yield. Abdominal pain was the most common symptom $(90 \%)$ and an abdominal mass the most common abnormal physical finding (58\%). A nodular mucosa with areas of ulceration was the usual colonoscopic finding. Ileocaecal disease was found in 16, ileocaecal and contiguous ascending colon disease in 14, segmental colonic tuberculosis in 13, ileocaecal disease and non-confluent involvement of another part of the colon in five, and pancolitis in two patients. This report emphasises that colonoscopy is a useful procedure for diagnosing colonic tuberculosis and that segmental colonic tuberculosis is not uncommon.
\end{abstract}

The ability to diagnose colonic tuberculosis by the now widely available technique of colonoscopy, ${ }^{12}$ the increase in extra pulmonary tuberculosis in the West, ${ }^{34}$ and the likelihood that intestinal tuberculosis will be increasingly seen in patients with AIDS, has once again focused attention on intestinal tuberculosis. Fewer than 100 colonoscopically diagnosed patients with colonic tuberculosis have been reported so far.

The present study describes the clinical and colonoscopic features of 50 consecutive patients with colonic tuberculosis, and emphasises that contrary to published data, ${ }^{5}$ segmental colonic tuberculosis (colonic tuberculosis without involvement of the caecum) is not uncommon, and that colonic tuberculosis can often be diagnosed by histological examination of mucosal biopsies obtained at colonoscopy.

\section{Methods}

PATIENTS

The hospital records of all patients diagnosed to have colonic tuberculosis in this department during the last 10 years were analysed. Colonoscopy had been performed in all these patients with an Olympus colonoscope after bowel preparation with either mannitol saline or a polyethylene glycol electrolyte solution. ${ }^{6}$ Six to eight biopsies from the lesions were taken for histological examination. These biopsies included the edge and base of an ulcer when present. Bouins solution was used as the fixative. Serial sections were cut and six slides with six sections each were made and alternate slides stained with haemotoxylin and eosin for evaluation. Two to three additional biopsies were collected in sterile $0.9 \%$ sodium chloride and homogenised. Smears prepared from the homogenate were stained with the Auramine $\mathrm{O}$ fluorescence acid fast stain and examined under a fluorescence microscope for fluorescing bacilli. The homogenate was also cultured on Lownstein Jensen medium and the presence of Mycobacterium tuberculosis on the culture slopes confirmed using standard methods. ${ }^{7}$

\section{Results}

Colonic tuberculosis was diagnosed in 50 patients during this 10 year study period. Sixteen had disease confined to the ileocaecal region, 14 had ileocaecal and contiguous involvement of variable lengths of the ascending colon, 13 had segmental colonic tuberculosis with involvement of the ascending colon in five, transverse colon in six, and descending colon in two. Five had ileocaecal and non-confluent involvement of another part of the colon, and in two the entire colon was affected.

Abdominal pain occurred in $90 \%$, weight loss in $74 \%$, anorexia in $60 \%$ and fever and diarrhoea in $56 \%$ of all patients. None had pulmonary symptoms.

A firm, usually tender abdominal mass of variable size $(58 \%)$, and ascites $(10 \%)$ were the only abnormal physical findings. The erythrocyte sedimentation rate was raised $(>30$ $\mathrm{mm} / \mathrm{h}$ ) in 38 of the 50 patients.

Chest radiographs showed evidence of healed tuberculosis (fibrosis and/or calcification) in nine patients and active pulmonary tuberculosis (presence of acid fast bacilli in the sputum and/or gastric juice) in seven patients with ileocaecal disease and in both patients with pancolitis.

\section{COLONOSCOPY}

Ulcerated areas a few millimetres up to $2 \mathrm{~cm}$ long, and a nodular friable mucosa were the most common lesions. These were often present in the same patient. The areas of ulceration were superficial and generally had sharply defined but irregular margins. The ulcer base was not friable and was covered with slough which was difficult to wash away. The surrounding mucosa was nodular and hyperaemic and blended imperceptibly with normal mucosa. In two patients numerous pale, polypoidal mucosal lesions of variable size arising from a slightly hyperemic mucosa were seen, and in one patient a solitary linear ulcer in the caecum was present. When the ileocaecal valve was involved it was oedematous and deformed and usually had areas of superficial ulceration. In the two patients with diffuse involvement of the colon, the mucosa from the rectum to the caecum was hyperaemic and friable 


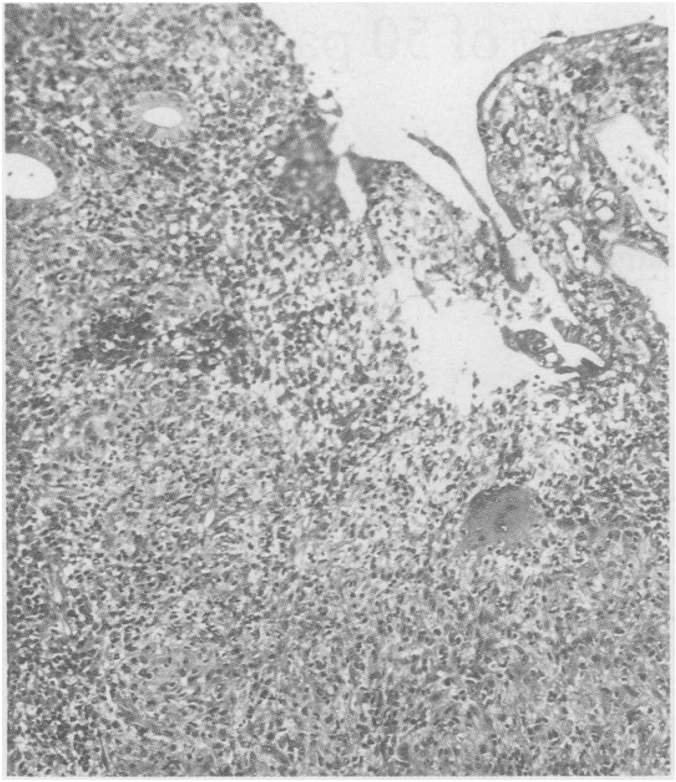

Figure 1: Photomicrograph $(H \mathcal{E} E)$ showing an ulcer in the colonic mucosa with the base lined by granulation tissue with many epithelioid cells and occasional giant cells.

and had areas of circumferential ulcerations of different sizes along the entire length of the colon. In all patients biopsies were taken from the base and the edge of ulcers when present, from the areas of nodularity and from adjacent normal looking mucosa.

\section{HISTOLOGY}

The diagnosis of tuberculosis was made histologically on colonoscopically taken mucosal biopsies in $\mathbf{4 0}$ of the 50 patients. Thirty seven of these 40 biopsies showed areas of ulceration, the base of which contained loosely arranged small clusters or larger compact agglomeration of epithelioid cells beneath the granulation tissue (Fig 1). Langhans giant cells were also present in 24 and focal areas of caseation in nine of these biopsies. These features were considered adequate to establish a diagnosis of tuberculosis. Of the 40 biopsies, 27 biopsies also showed nonulcerated areas, in addition to areas of ulceration which showed features suggestive of tuberculosis, and contained mucosa and submucosa. Compact clusters of epithelioid cells (Fig 2) or well formed granulomas were present only in the mucosal lamina propria in six biopsies, in the submucosa only in seven biopsies (Figs 3a, b), and in both the mucosa and the submucosa in 11 biopsies, while three biopsies showed only chronic non-specific inflammation in the nonulcerated area. Epithelioid collections were present in 10 of the 13 biopsies which contained only mucosal lamina propria.

In 10 patients the biopsies had features of chronic inflammation but no granulomas, caseation or collection of epithelioid cells. The diagnosis of tuberculosis was confirmed in specimens of colon resected at laparotomy in two of these patients. Of the remaining eight patients, three had evidence of pulmonary tuberculosis for which treatment was initiated. Five patients were started on treatment for tuberculosis empirically. All 50 patients responded dramatically to stan-

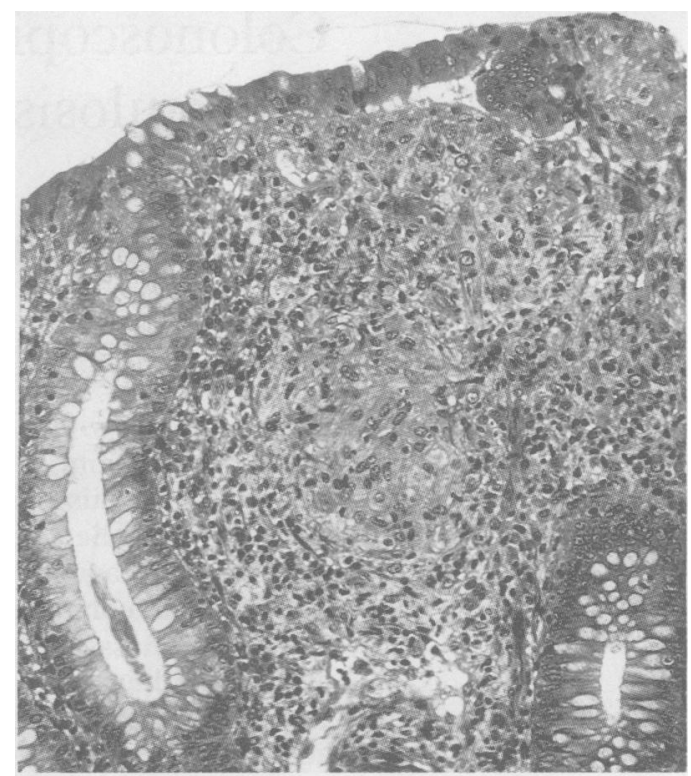

Figure 2: Colonic mucosa with focal compact collection of epithelioid cells in the lamina propria.

dard therapy for tuberculosis with diminution of abdominal pain and fever, and improvement in appetite and weight gain.

No fluorescing bacilli were seen in any of the smears prepared from the tissue homogenates and Mycobacterium tuberculosis was cultured from only three of the 50 biopsies. In all three the histology was suggestive of tuberculosis.

\section{Discussion}

The present report confirms published data that the caecum is most often affected in colonic tuberculosis. ${ }^{8-10}$ This is probably because the caecum is an area of physiological stasis, and a site of avid water and electrolyte absorption and relatively little digestive activity. These factors permit prolonged contact between the bacilli and the caecal mucosa. ${ }^{11}{ }^{12}$ Segmental colonic tuberculosis was diagnosed in $26 \%$ of patients in this series, suggesting that this form of colonic tuberculosis may not be as uncommon as previously believed. ${ }^{13-15}$ Whether this observation reflects a change in the presentation of colonic tuberculosis or improved diagnostic capability is not clear from this study. Earlier reports on segmental colonic involvement suggested that the sigmoid colon was most frequently involved. ${ }^{16}$ More recent reports, including the present study show that the ascending and transverse colon are usually affected.'

The symptoms in caecal tuberculosis and in segmental involvement are similar. Abdominal pain which has no diagnostic characteristics is the most frequently reported symptom ${ }^{17-19}$ although in at least one report diarrhoea was the most common complaint. ${ }^{20}$ The pain is most frequently lower abdominal, but can be felt in any part of the abdomen especially when there is associated small bowel involvement. Colicky pain suggests the presence of intestinal obstruction, while the less common continuous dull ache suggests peritoneal inflammation. Weight loss is common ${ }^{21}$ and occurred in $74 \%$ of our patients. Weight loss could be the result of increased 


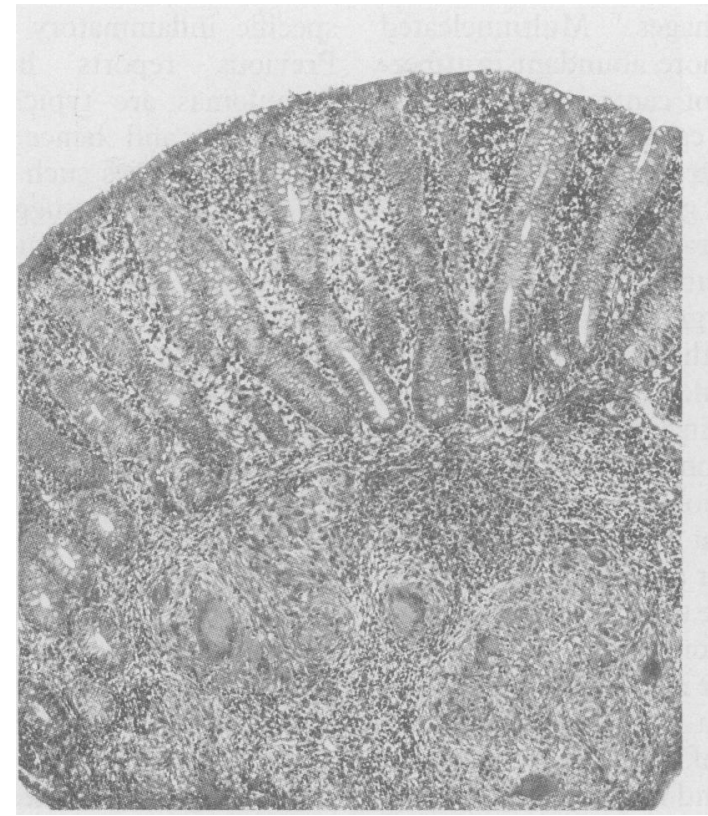

Fig $3 A$

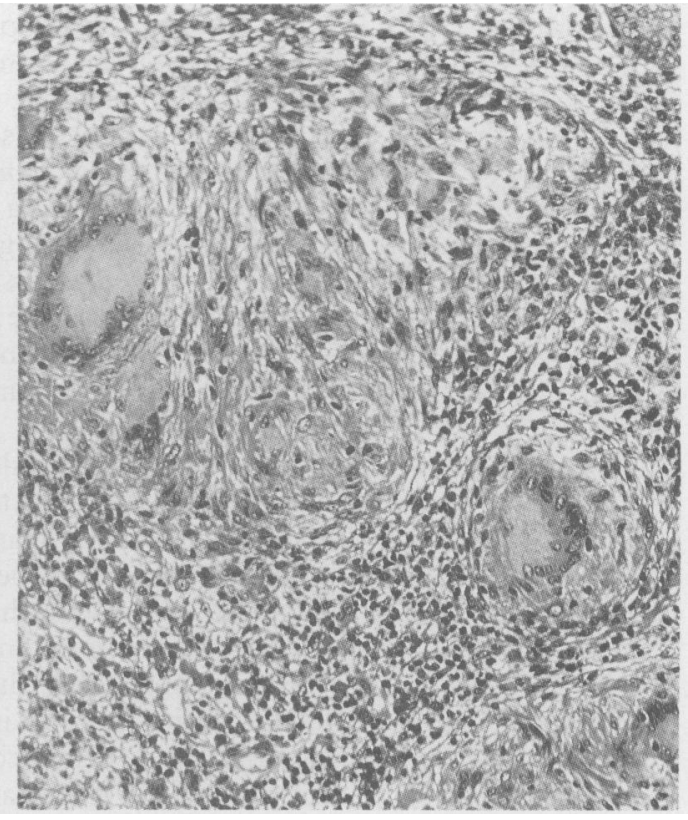

Fig $3 B$

Figure 3: Histology of colonic mucosa showing many granulomata in the submucosa (a). High power view (b); of a granuloma showing epithelioid cells and giant cells surrounded by lymphocytes.

catabolism subsequent to infection, ${ }^{22}$ malabsorption secondary to small bowel bacterial overgrowth, ${ }^{23}{ }^{24}$ increased bile salt losses from the ileum, ${ }^{25}$ anorexia, and postprandial abdominal discomfort. ${ }^{26}$

In primary colonic tuberculosis clinical examination may be entirely normal or reveal evidence of an abdominal mass or ascites. The mass can be made of thickened colon, ${ }^{21}$ lymph nodes, mesenteric fat and omentum. ${ }^{27}$ In all our patients, except the two with diffuse involvement in whom ulcerative colitis was diagnosed at colonoscopy, the patient with a solitary caecal ulcer in whom a diagnosis of tuberculosis was made, and the two patients with polypoidal lesions, a colonic neoplasm was considered in the differential diagnosis because there are no clinical or colonoscopic features diagnostic of colonic tuberculosis. Other diseases which should be considered in the differential diagnosis include ameboma, periappendicular abscess, colonic lymphoma, ulcerative colitis and Crohn's disease.$^{27}{ }^{28}$ Colonoscopic differentiation between tuberculosis of the colon and Crohn's colitis can be difficult. ${ }^{2}$ The changes caused by acute inflammation of the colonic mucosa - namely, oedematous mucosal folds, mucosal ulcerations and nodularity, luminal narrowing, strictures and pseudopolyps, can occur in both conditions. ${ }^{29}$ Small aphthous ulcers were considered specific for Crohn's colitis. ${ }^{30}$ Small aphthous ulcers, however, have recently been described in tuberculous colitis, ${ }^{2}$ but are distinctly uncommon. In the present series no patient was found to have aphthous ulcers. The focal erosions referred to as erythematous mucosal plaques, which are believed to represent a preaphthous ulcer phase have been described in Crohn's colitis $^{31}$ but not, so far, in tuberculous colitis. Although ulcers in both conditions can be of variable size, shape and depth, in tuberculosis the ulcers are generally transverse and the mar- gins sharply defined with surrounding erythema. Deep, tortuous ulcers are more commonly seen in Crohn's colitis but, in contrast with tuberculosis, reactive mucosal change surrounding the ulcer is characteristically absent. ${ }^{32}$ But perhaps the most important distinguishing feature is that the ulcers in Crohn's disease occur on a normal appearing mucosa ${ }^{32}$ whereas in tuberculous colitis the mucosa surrounding the ulcer has features of inflammation such as erythema, nodularity or oedema. Although a cobblestone appearance of the mucosa has been reported in tuberculosis of the colon ${ }^{27}$ its presence is strongly suggestive of Crohn's disease.$^{30}$ Both diseases can result in deformity, nodularity and ulceration of the ileocaecal valve. A patulous ileocaecal valve with surrounding heaped up folds ${ }^{20}$ or one which is destroyed by disease ${ }^{1}$ is, however, more likely to be the result of tuberculosis than Crohn's disease. Rectal involvement is rare in tuberculosis but occurs to a variable extent in about $70 \%$ of all patients with Crohn's colitis. ${ }^{33}$ Colonic strictures caused by tuberculosis are generally but not invariably short $<3 \mathrm{~cm}^{27}$ and mucosal bridging has not been described in tuberculous colitis.

Although colonic tuberculosis and Crohn's colitis are regarded as granulomatous disorders, differences in the appearance of the granulomas and other histological features can sometimes help distinguish between these two conditions. In tuberculosis the granulomas can be larger and vary in appearance from a diffuse collection of epithelioid cells to compact collections of oval or spindle shaped epithelioid cells which have abundant pale cytoplasm and oval, pale vesicular nuclei. ${ }^{27}$ Confluent granulomas are strongly suggestive of tuberculosis. ${ }^{3+}$ In contrast, in Crohn's disease the granulomas are not confluent even though two or three may lie in close proximity. ${ }^{2+}$ These granulomas are typically comprised of closely packed aggregates of eosinophilic epithe- 
lioid cells and macrophages. ${ }^{35}$ Multinucleated giant cells are usually more abundant in tuberculosis. ${ }^{27}$ The presence of central caseation is a hallmark of granulomas caused by tuberculosis, but small areas of central necrosis can occasionally be seen in a granuloma caused by Crohn's disease. ${ }^{27}$ The granulomas as a result of tuberculosis are always surrounded by inflammatory cells, whereas the granulomas of Crohn's disease can occur in an otherwise normal biopsy, particularly in the rectum..$^{36}$

The ulcerated area in tuberculosis almost always shows a granulomatous response with loosely arranged collections of epithelioid cells and multinucleated giant cells with or without granulomas in the deeper aspects of the biopsies but in Crohn's disease the ulcers and fissures may not always show granulomas. ${ }^{27}$

Unlike tuberculosis the inflammatory infiltrate in the lamina propria in Crohn's colitis shows variation in the density of the infiltrate in different parts of the biopsy and has been regarded as the histological counterpart of the macroscopic patchy inflammation. ${ }^{37}$

Scanning electron microscopy has shown goblet cell hyperplasia and increased mucus secretion $^{38}$ while axonal degeneration has been shown by electron microscopy in Crohn's disease. ${ }^{39}$ It is not clear whether these findings are specific for Crohn's disease because similar studies in intestinal tuberculosis have not been done. The demonstration of acid fast bacilli in tissue sections is, however, diagnostic of tuberculosis.

Although these colonoscopic and histological features will often help distinguish colonic tuberculosis from Crohn's colitis, as with any other disease all the facts pertaining to the patient must be taken into consideration before arriving at a diagnosis. Thus in a patient with equivocal colonoscopic and histological findings, the absence of internal and cutaneous fistulae, fissures, perianal and ischiorectal abscesses (which occur in over $50 \%$ of patients with Crohn's colitis ${ }^{40}$ ) or extraintestinal manifestations such as skin lesions, uveitis, iritis, liver disease, arthralgia and arthritis (which occur in approximately $20 \%$ of patients with Crohn's colitis $^{41}$ ) would strongly favour a diagnosis of tuberculosis in which condition these complications are rare. No patient in the present study had perianal complications, extraintestinal manifestations such as uveitis or arthritis, fistulae or colonic perforation. ${ }^{42}$

Initial reports suggested that the diagnostic yield in colonic tuberculosis by colonoscopy was poor. ${ }^{434}$ Moshal et $a l^{44}$ were unable to diagnose colonic tuberculosis by colonoscopy in any of their nine patients who were subsequently diagnosed at laparotomy to have the disease. The present report, however, confirms the results of more recent reports in adults ${ }^{129}$ and in children ${ }^{46}$ that colonoscopy is a useful method of diagnosing colonic tuberculosis. Factors which influence the diagnostic yield of colonoscopic biopsies include the number of biopsies taken and sections examined, ${ }^{47}$ the age of the lesions, because in early lesions the characteristic granulomas with caseation may not have developed, ${ }^{27}$ and previous therapy for tuberculosis because treatment can alter the characteristic histology so that only non- specific inflammatory changes are present. ${ }^{2127}$ Previous reports have emphasised that granulomas are typically found in the submucosa $a^{2043}$ and hence cannot be detected in mucosal biopsies such as those taken at colonoscopy. Our data suggest that this is not true because careful evaluation of the base of ulcers will often show epithelioid cell clusters and granulomas (Fig 1) and submucosa is often obtained in colonoscopic biopsies. The question of how many biopsies should be taken remains unresolved. It is our policy to take a minimum of six biopsies including the floor of an ulcer.

Culture of homogenised mucosal biopsies may be useful because Mycobacterium tuberculosis can be cultured from the homogenate even when histological examination shows a non-specific inflammatory response. ${ }^{48}$ The reason for the low culture yield in the present report could be because only two to three biopsies were cultured.

Occasionally despite careful histological and bacteriological studies on colonoscopically obtained colonic mucosal biopsies from patients suspected to have colonic tuberculosis and careful clinical examination, proof of tuberculosis is not forthcoming as happened in five of our patients. In such instances we believe as do others ${ }^{18}$ that it is justifiable to treat these patients empirically rather than subject them to a diagnostic laparotomy. This is because the response to treatment is usually dramatic. A sense of well being prevails usually within 10 days, the fever and abdominal pain always subside within three weeks of starting antituberculosis therapy and there is rapid weight gain particularly in those patients with a previous history of weight loss. Patients with symptoms of subacute intestinal obstruction due to tuberculous strictures should not be subjected to surgery initially because these patients generally respond well to medical treatment. ${ }^{49}$ Surgery should be reserved for complications such as perforation, fistula formation, and complete intestinal obstruction.

In conclusion, this report suggests that segmental colonic tuberculosis is not as uncommon as previously believed, that colonoscopy is a useful means of obtaining tissue from which a diagnosis can usually be made by light microscopy and that histological or microbiological proof of tuberculosis may not be essential in all patients before initiating therapy.

The Wellcome Research Unit is supported by the Wellcome Trust, London, UK in association with the Christian Medical College Lospital, Vellore, India.
Hond

1 Bhargava DK, Tandon HD, Chawla TC, Shriniwas, Tandon BN, Kapur BML. Diagnosis of ileocaecal and colonic tuberculosis by colonoscopy. Gastrointest Endos 1985; 31: 68-70.

2 Ferentzi CV, Sieck JO, Ali MA. Colonoscopic diagnosis and medical treatment of ten patients with colonic tuberculosis. Endoscopy 1988; 20: 62-5.

3 Breit R. Non-pulmonary tuberculosis in Australia. Med F Aust 1982; 2: 479-80.

4 Schofield PF. Abdominal tuberculosis. Gut 1985; 26: 1275-8. Chawla S, Mukerjee P, Bery K. Segmental tuberculosis of the colon (a report of 10 cases). Clin Radiol 1971; 22: 104-9.

6 DiPalma JA, Brady III CE, Stewart DL, Karlin DA, McKinney MK, Clement DJ, et al. Comparison of colon cleansing methods in preparation for colonoscopy. Gastroenterology 1984; 86: 856-60.

7 Sommers HM, Good RC. Mycobacterium. In: Lennette EH Balows A, Hausler WJ Jr, Shadomy HJ, eds. Manual of clinical microbiology. 4th ed. Washington: American Society for Microbiology, 1985: 216-48.

8 Bentley G, Webster JHH. Gastrointestinal tuberculosis: a 10year review. BrF Surg 1967; 54: 90-6. 
9 Gupta OP, Dube MK. Tuberculosis of gastrointestinal tract with special reference to rectal tuberculosis. Indian $\mathcal{F} \mathrm{Med}$ Res 1970; 58: 979-84

10 Klimach OE, Ormerod LP. Gastrointestinal tuberculosis: a retrospective review of 109 cases in a district general hospital. Qf Med 1985; 56: 569-78.

11 Hoon JR, Dockerty MB, Pemberton de J. Ileocecal tuberculosis including a comparison of this disease with nonspecific regional enterocolitis and noncaseous tuberculated specific regional enterocolitis and noncaseous

12 Rankine JA. Tuberculosis of the ileocaecal area. F Int $\mathrm{Col} \mathrm{Surg}$ 952; 18: 202-9.

13 Aronson AR, Slattery LR. Tuberculosis of the transverse colon: report of a case simulating carcinoma. Gastroenterology 1959; 36: 698-701.

14 Angelchik J, Thabit G Jr, Hall JH. Segmental tuberculosis of the colon. Postgrad Med 1962; 32: 462-6.

15 Rhoades ER, Klein LJ, Walsh JD. A case of probable tuberculosis of the distal colon. Gastroenterology 1960;38: 645-58.

16 Hancock DM. Hyperplastic tuberculosis of the distal colon. Brf Surg 1958; 46: 63-8.

17 Bhansali B. Abdominal tuberculosis. Am f Gastroenterol 1977; 67: 324-37.

18 Palmer KR, Patil DH, Basran GS, Riordan JF, Silk DBA. Abdominal tuberculosis in urban Britain - a common disease. Gut 1985; 26: 1296-305

19 Schulze K, Warner HA, Murray D. Intestinal tuberculosis: experience at a Canadian teaching institution. $\mathrm{Am} \mathcal{F ~ M e d}$ 1977; 63: 735-45.

20 Aoki G, Nagasako K, Nakae Y, Suzuki H, Endo M, Takemoto $T$. The fibercolonoscopic diagnosis of intestinal tuberculosis. Endoscopy 1975; 7: 113-21.

21 Anand SS. Hypertrophic ileocaecal tuberculosis in India with a record of fifty hemicolectomies. Ann R Coll Surg 1956; 19: 205-22.

22 Klish WJ. Nutritional metabolic consequences of acute diarrhea in children. In: Bellanti JA, ed. Acute diarrhea: its nutritional consequences in children. New York: Raven Press, 1983: 97-107.

23 Tandon RK, Bansal R, Kapur BML, Shriniwas. A study of malabsorption in intestinal tuberculosis: stagnant loop syndrome. Am F Clin Nutr 1980; 33: 244-50.

24 Pimparker BD, Dhonde UM. Intestinal tuberculosis: gastrointestinal absorption studies. F Assoc Physicians India 1974; 22: 219-28.

25 Desai HG, Zaveri MP, Antia FP. Bile salt metabolism in intestinal tuberculosis - increased glycine:taurine ratio of conjugated bile salts. Indian 7 Med Res 1975; 63: conjugated

26 Paustian FF, Monto GL. Tuberculosis of the intestines. In: Bockus HL, ed. Gastroenterology. Vol 2. 3rd ed. Philadelphia: WB Saunders, 1976: 750-77.

27 Tandon HD, Prakash A. Pathology of intestinal tuberculosi and its distinction from Crohn's disease. Gut 1972; 13: 260-9.

28 Lewis EA, Kolawole TM. Tuberculous ileo-colitis in Ibadan: a clinico-radiological review. Gut 1972; 13: 646-53.

29 Kalvaria I, Kottler RE, Marks IN. The role of colonoscopy in the diagnosis of tuberculosis. $\mathcal{F}$ Clin Gastroenterol 1988; 10: $516-23$.
30 Hogan WJ, Hensley GT, Geenen JE. Endoscopic evaluation of inflammatory bowel disease. Med Clin North Am 1980; 64: 1083-102.

31 Watier A, Devroede G, Perey B, Haddad H, Madarnas P, Grand-Maison P. Small erythematous mucosal plaques: an endoscopic sign of Crohn's disease. Gut 1980; 21: 835-9.

32 Blackstone MO. Inflammatory bowel disease. In: Endoscopic interpretation: normal and pathologic appearances of the gastrointerpretation: normal and pathologic appearances of the
intestinal tract. New York: Raven Press, 1984: 464-94

33 Mekhiian HS, Switz DM, Melnyk CS, Rankin GB, Brooks RK. Clinical features and natural history of Crohn's disease. RK. Clinical features and natural his

34 Talbot IC, Price AB. Crohn's disease. In: Biopsy pathology in colorectal disease. London: Chapman and Hall, 1987: 13548.

35 Chambers TJ, Morson BC. The granuloma in Crohn's disease. Gut 1979; 20: 269-74

36 Surawicz CM, Meisel JL, Ylvisaker T, Saunders DR, Rubin CE. Rectal biopsy in the diagnosis of Crohn's disease: value of multiple biopsies and serial sectioning. Gastroenterology 1981; 81: 66-71.

37 Yardley JH, Donowitz M. Colorectal biopsy in inflammatory bowel disease. In: Yardley JH, Morson BC, Abell MR, eds. The gastrointestinal tract. International Academy of Pathology Monograph. Baltimore: Williams and Wilkins, 1977: $50-94$

38 Dvorak AM, Connell AB, Dickersin GR. Crohn's disease: a scanning electron microscopic study. Hum Pathol 1979; 10: 165-77.

39 Dvorak AM, Silen W. Differentiation between Crohn's disease and other inflammatory conditions by electron microscopy. Ann Surg 1985; 201: 53-63.

40 Williams DR, Coller JA, Corman ML, Nugent W, Veidenheimer MC. Anal complications in Crohn's disease. Dis Colon Rectum 1981; 24: 22-4.

41 Meyers S, Janowitz HD. Crohn's disease: extraintestinal manifestations. In: Berk JE, Haubrich WS, Kalser MH, manifestations. In: Berk JE, Haubrich WS, Kalser MH, Roth JL, Schaffner F, eds. Gastroenterology. 4th
delphia: WB Saunders Company, 1985: 2259-67.

42 Eggleston FC, Deodhar MC, Kumar A. Tuberculous perforation of the bowel - results in 21 cases. Trop Gastroenterol 1983; $4: 164-7$

43 Devanesan JD, Sable RA, Pitchumoni CS, Lev R, Zapiach L. Segmental tuberculosis of the colon mimicking carcinoma. Arch Surg 1980; 115: 90-1.

44 Moshal MG, Baker LW, Lautre G, Bader E. Colonoscopy: 100 examinations. S Afr F Surg 1973; 11: 73-8.

45 Bhargava DK, Tandon HD. Ileocecal tuberculosis diagnosed by colonoscopy and biopsy. A ust NZ F Surg 1980; 50: 583-5.

$46 \mathrm{Tam}$ PKH, Saing H, Lee JMH. Colonoscopy in the diagnosis of abdominal tuberculosis in children. Aust Paediatr 1986; 22: $143-4$.

47 Franklin GO, Mohapatra M, Perrillo RP. Colonic tuberculosis diagnosed by colonoscopic biopsy. Gastroenterology 1979; 79: $362-4$.

48 Bhargava DK, Shrinivas, Tandon BN, Kiran U, Chawla TC, Kapur BML. Serodiagnosis of intestinal tuberculosis by the soluble antigen fluorescent antibody test (SAFA test). 7 Trop Med Hyg 1986; 89: 61-5.

49 Anand BS, Nanda R, Sacdev GK. Response of tuberculous stricture to antituberculous treatment. Gut 1988; 29: 62-9. 